\title{
Ágata associada ao magmatismo do Cretáceo da Bacia do Paraná, sul do Brasil
}

\author{
Cassiana Roberta Lizzoni MICHELIN ${ }^{1}$, Ana Maria Pimentel MIZUSAKI ${ }^{1}$, Valderez FERREIRA², Tânia Mara \\ Martini de BRUM ${ }^{1}$ \& Leo Afraneo HARTMANN ${ }^{1}$
}

1.Universidade Federal do Rio Grande do Sul, Instituto de Geociências. Av. Bento Gonçalves, 9500, CEP 91.540-000, Porto Alegre, Rio Grande do Sul, Brasil.E-mail: cassimichelin@gmail.com, ana.mizusaki@ufrgs.br, labogem@ufrgs.br, leo.hartmann@ufrgs.br.

2.Universidade Federal de Pernambuco, Centro de Tecnologia e Geociências. Av. Acadêmico Hélio Ramos s/n, Cidade Universitária, CEP 50740-530, Recife, Pernambuco, Brasil. E-mail: valderez@ufpe.br.

Recebido em 12/2011. Aceito para publicação em 06/2013.

Versão online publicada em 12/11/2013 (www.pesquisasemgeociencias.ufrgs.br)

\begin{abstract}
Resumo - Na porção sul do Brasil, especialmente na região denominada Distrito Mineiro de Salto do Jacuí (Rio Grande do Sul), localizam-se os maiores depósitos mundiais de ágata, associados às rochas vulcânicas cretáceas da Formação Serra Geral, Bacia do Paraná. A ágata é uma variedade de calcedônia com bandamento, onde as bandas se dispõem de forma concêntrica ou paralela no interior de cavidades denominadas geodos. Na região, ocorre a valorizada ágata denominada Umbu, de cor azul escura e com elevada microporosidade que a torna adequada para tingimento com corantes. Neste trabalho procurou-se caracterizar a ágata sob o ponto de vista químico, isotópico e petrográfico por meio de técnicas analíticas diversas. Verifica-se que a temperatura de formação das ágatas varia de $23^{\circ}$ a $65^{\circ} \mathrm{C}$ com base em isótopos de oxigênio. Estas temperaturas estão relacionadas com vários parâmetros, tais como o teor total de sílica, a presença de impurezas (como o $\mathrm{Fe}_{2} \mathrm{O}_{3}$ ), o teor de água na estrutura e a cristalinidade. As amostras analisadas caracterizam-se por diferenças marcantes nos teores de elementos maiores e traços, na temperatura de cristalização e na cristalinidade, o que indica que apesar de serem ágatas provenientes de uma mesma região, ocorrem variações no seu processo de cristalização. Isto resulta nas diferentes estruturas e colorações apresentadas pelas ágatas da região de Salto do Jacuí.
\end{abstract}

Palavras-chave: ágata, química mineral, isótopos estáveis, Formação Serra Geral.

Abstract -Agate deposits in Cretaceous magmatism in the Paraná Basin, Southern Brazil. The Salto do Jacuí Mining District, located in Rio Grande do Sul state (southern Brazil) is highlighted by the most important agate deposits in the world. This occurrence is associated with the Serra Geral Formation, an important Cretaceous magmatism in the Paraná Basin. Agate is a special variety of chalcedony characterized by a banded structure and found in geodes. It is important to register the presence of the named Umbu agate which has a great value by the uncommon dark blue color and high microporosity that makes it suitable for dyeing process. In this study we try to characterize the agate mineralization using chemical, petrographic and isotopic analytical techniques. Based on oxygen isotopes, the temperatures of agate formation range from 23 to $65^{\circ} \mathrm{C}$, and these values can be related to parameters such as the total content of silica, the presence of impurities (like $\mathrm{Fe}_{2} \mathrm{O}_{3}$ ), the water content in the structure and the crystallinity. So, the analyzed agate samples are characterized by marked differences in major and trace elements, the crystallization temperature and degree of crystallinity indicating variations in the crystallization process despite the common occurrence in the SJMD.

Keywords: agate, mineral chemistry, stable isotope, Serra Geral Formation.

\section{Introdução}

A calcedônia é uma variedade microcristalina de quartzo caracterizada como um agregado de quartzo micro- a criptocristalino, granular a fibroso e microporoso. Os microporos podem ter diâmetros de até 0,1 $\mu \mathrm{m}$ e contêm água. A ágata é uma variedade de calcedônia com bandamento onde as bandas se dispõem de forma concêntrica ou paralela no interior de cavidades denominadas geodos (Frondel, 1962; Hurlbut Jr. \& Switzer, 1980; Heemann, 2005). A ágata ocorre associada tanto à rochas sedimentares como vulcânicas, e as ocorrências mais importantes têm sido relacionadas com as vulcânicas do tipo extrusivo (Flörke et al., 1982). Na porção sul do Brasil, especialmente na região denominada de Salto do Jacuí, Estado do Rio Grande do 
Sul, estão localizados os maiores depósitos mundiais, em volume de ágata. São jazidas que estão associadas com as rochas vulcânicas cretáceas que constituem a Formação Serra Geral da Bacia do Paraná.

O maior polo de exploração e comercialização de ágata é o Distrito Mineiro de Salto do Jacuí (DMSJ), que se caracteriza por ser a única ocorrência mundial da ágata denominada Umbu. Trata-se de uma ágata muito valorizada devido à sua coloração azul escura homogênea e à elevada microporosidade que a torna adequada para tingimento com corantes. Este processo é muito empregado no seu beneficiamento, permitindo que adquira um valor comercial mais elevado (Heemann, 2005).

Neste trabalho, foram coletadas amostras de ágata do DMSJ para realização de análises petrográficas, químicas e isotópicas visando à sua caracterização mais detalhada. Isto porque a maioria dos trabalhos realizados na região refere-se à caracterização da geologia do depósito, e não da ágata (Heemann, 1997, 2005; Strieder \& Heemann, 2006).

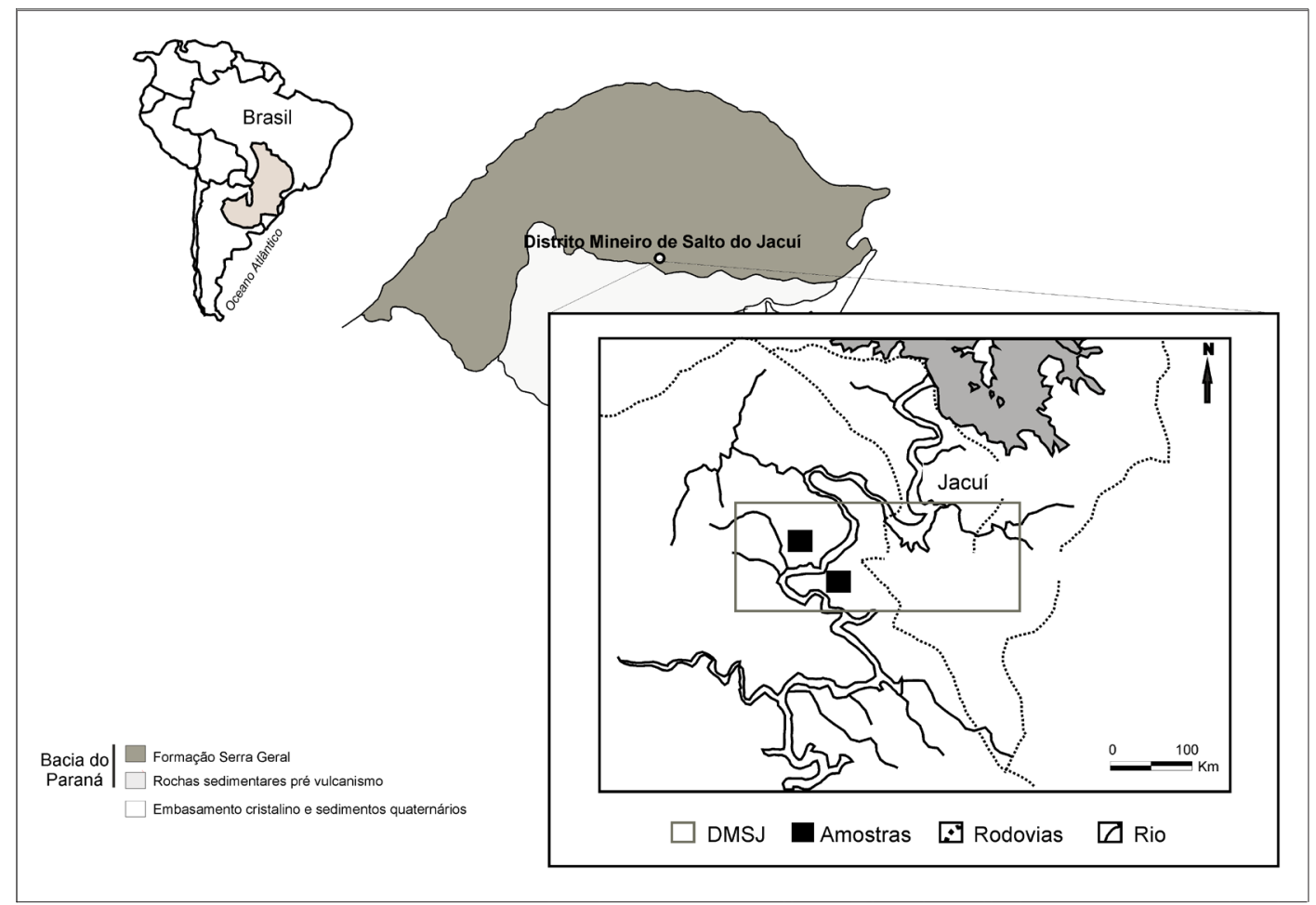

Figura 1. Localização do Distrito Mineiro de Salto do Jacuí (DMSJ), Bacia do Paraná, Rio Grande do Sul, Brasil.

\section{2 Área, materiais e métodos}

\subsection{Geologia do Distrito Mineiro de Salto do Jacuí (DMSJ)}

O DMSJ está inserido na Bacia do Paraná, que é uma das bacias paleozóicas da plataforma sul-americana. Sua área abrange aproximadamente 1,6 milhões de $\mathrm{km}^{2}$, se estendendo pela porção sul do Brasil e países limítrofes, Paraguai, Argentina e Uruguai. Apresenta um formato alongado na direção NNE-SSW, com aproximadamente $1.950 \mathrm{~km}$ de comprimento e largura média em $900 \mathrm{~km}$. A espessura do preenchimento, incluindo as rochas vulcânicas e sedimentares desta bacia, está em torno de $7.000 \mathrm{~m}$ no seu depocentro (Milani, 1997).

Nesta bacia são reconhecidas do ponto de vista estratigráfico, seis supersequências limitadas por discordâncias regionais e cuja abrangência temporal é de 400 Ma: Rio Ivaí, Paraná, Gondwana I, Gondwana II, Gondwana III e Bauru (Milani, 1997) (Fig. 2).

A supersequência Gondwana III (jurássico-eocretácea), reunindo as formações Serra Geral e Botucatu, é onde ocorre a mineralização de ágata no DMSJ. A Formação Botucatu representa um extenso deserto jurássico sobre o qual as rochas vulcânicas da Serra Geral extravasaram, embora haja indícios de persistência da atividade eólica ainda durante os primeiros derrames de lava (Scherer, 2000).

A Formação Serra Geral representa um evento magmático, sendo constituída por uma sucessão de derrames vulcânicos com espessuras remanescentes de até $2.000 \mathrm{~m}$. São petrograficamente reconhecidos basaltos toleíticos (90\%), andesitos basálticos (7\%) e subordinadamente riolitos e riodacitos (3\%) além de rochas intrusivas (Piccirillo et al., 1988; Peate et al., 1992). A idade absoluta para a Formação Serra Geral, com base no método Ar-Ar, é de $133 \pm 1 \mathrm{Ma}$, o que indica sua associação com a ruptura do Gondwana (Melfi et al., 1988; Renne et al., 1992).

Observa-se que na região do DMSJ há uma associação entre a presença dos arenitos eólicos da Formação Botucatu e a mineralização de ágata, situação descrita por autores como Strieder \& Heemann (2006). 


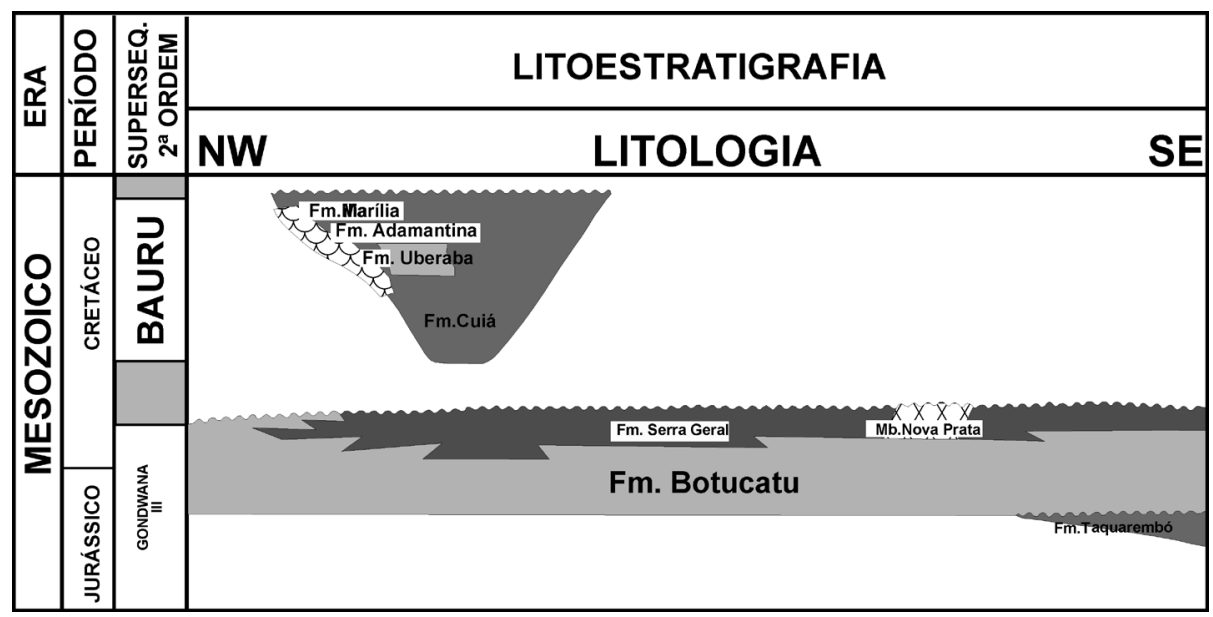

Figura 2. Coluna estratigráfica simplificada da Bacia do Paraná destacando as unidades estudadas (modificado de Milani, 1997).

\subsection{Distrito Mineiro de Salto do Jacuí (DMSJ)}

O DMSJ abrange uma área de aproximadamente $250 \mathrm{~km}^{2}$ e localiza-se no município de Salto do Jacuí, porção central do estado do Rio Grande do Sul (Fig. 1). Nesta ocorrência, a maioria das frentes de lavra de ágata está localizada nas proximidades das margens do Rio Jacuí e de seus afluentes e ocorrem numa cota altimétrica entre 200 e $260 \mathrm{~m}$. Os depósitos são do tipo geodo em basalto conforme proposição de Bossi \& Caggiano (1974).

Nesta região a ocorrência de ágata está associada aos derrames da Formação Serra Geral, onde também se observam intertraps e "diques" de arenito com orientação E-W e N-S. No DMSJ, para a Formação Serra Geral, Heemann $(1997,2005)$ propôs três associações de rochas vulcânicas: basalto intergranular, basaltos e dacitos glomeropórfiros e dacito holocristalino. Aquele autor destacou que as frentes de lavra estão associadas com os basaltos e dacitos glomeropórfiros onde são reconhecidas seis unidades vulcânicas. Nestas unidades, o autor destaca que o derrame mineralizado (denominado de P), que contém os geodos de ágata de melhor qualidade gemológica, é constituído de um basalto vesicular - amigdaloidal, cinza claro e textura hipohialina, alterado, com espessura de 4 a $6 \mathrm{~m}$. Outro derrame também portador de geodos é o DSVI (dacito semi-vítreo inferior) com espessura de 3 a $4 \mathrm{~m}$, caracterizado por apresentar matriz vítrea, cor preta e brilho resinoso, porém, fracamente mineralizado com geodos de ágata (Heemann, 2005) (Fig. 3).

Os geodos encontrados no derrame P (Fig. 3) pos-

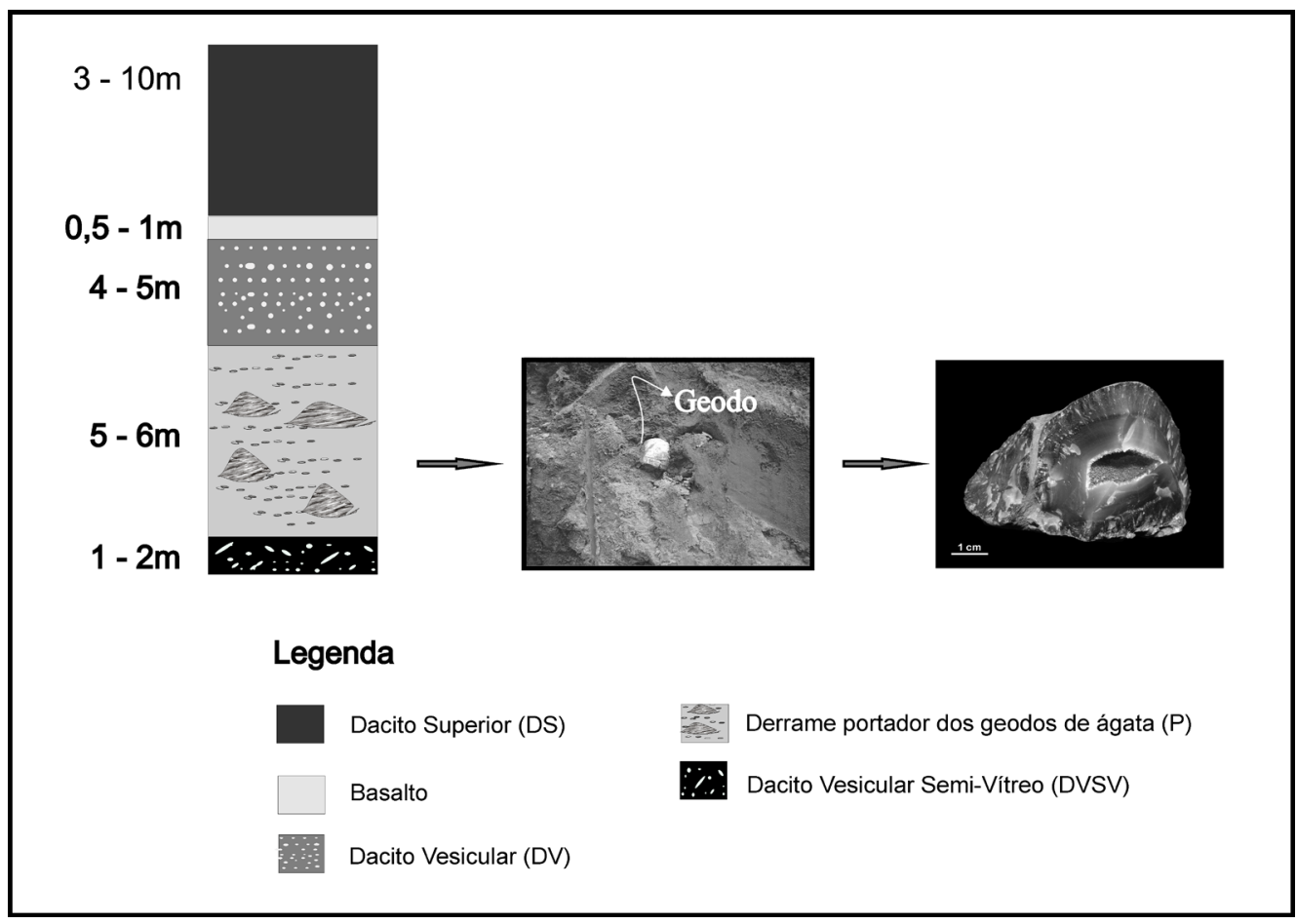

Figura 3. Perfil colunar esquemático da área de estudo (modificado de Heemann, 2005). 
suem forma elíptica-alongada, estão orientados e com diâmetros que variam entre 10 e $25 \mathrm{~cm}$, sendo a interface rocha hospedeira-geodo delimitada por uma camada milimétrica de material argiloso.

Nos geodos, da borda para o centro, de uma forma geral, observa-se a seguinte sequência de preenchimento: opala, ágata, quartzo macrocristalino, calcita. A ágata e o quartzo macrocristalino são as fases mais comuns, porém volumetricamente mais importantes. Por quartzo macrocristalino, define-se o quartzo incolor, bem cristalizado, associado com a ágata nos geodos.

Brum et al. (1998) mostraram que a ágata do DMSJ apresenta bandas com cores e tonalidades diferentes bem como variações na espessura, transparência, textura e microporosidade. Conforme a disposição destas bandas, os autores caracterizam e classificam macroscopicamente os diferentes tipos de ágata, propondo, com base nestes arranjos, três padrões macroscópicos básicos de bandamento: homogêneo, bandado e complexo (Fig. 4A).

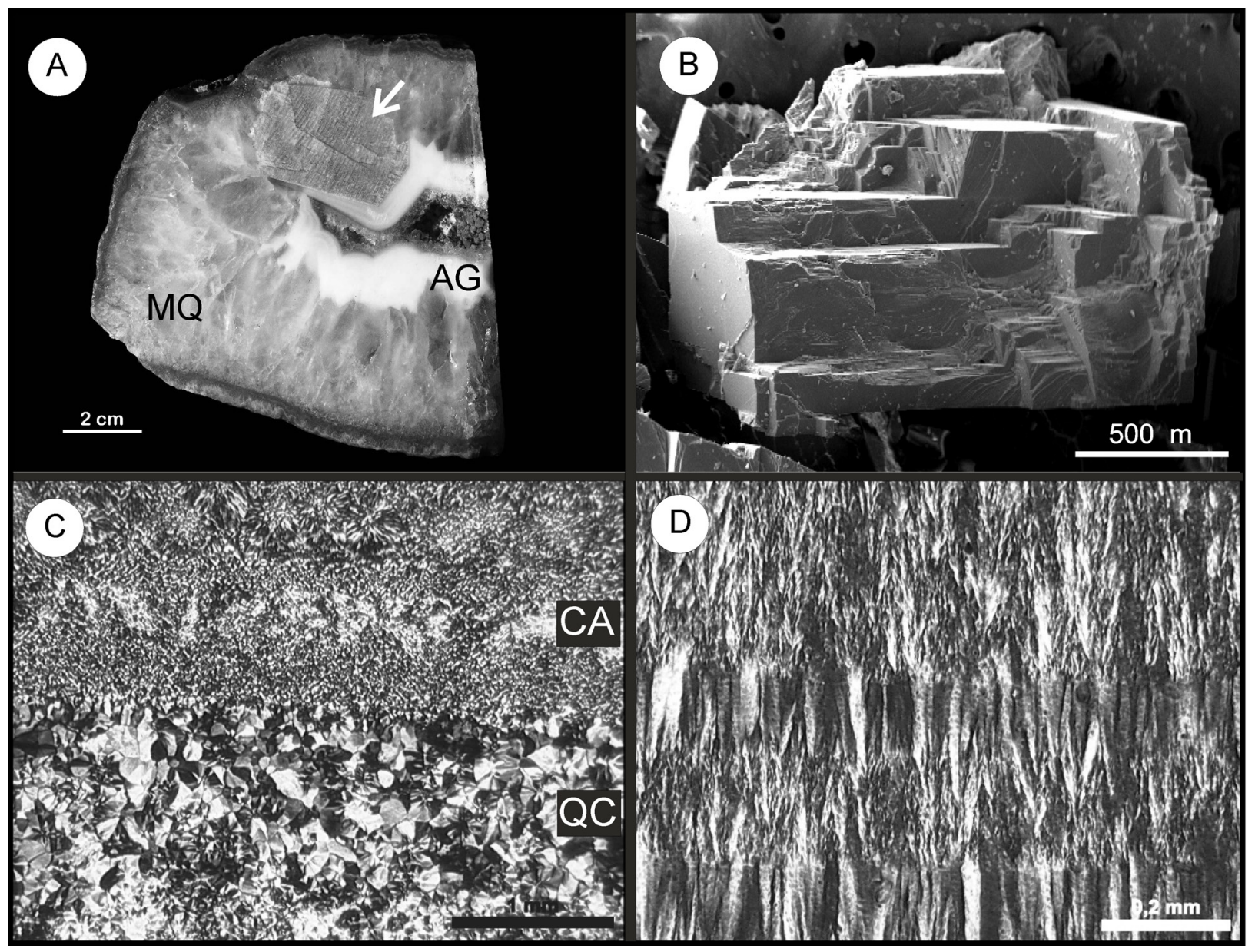

Figura 4. Fotomicrografia ao microscópio eletrônico de varredura. A. Geodo apresentando o padrão complexo de bandamento, com ágata (AG) e quartzo macrocristalino (QM). Observar a associação com cristais de calcita (indicados pela seta). B. Detalhe ao microscópio eletrônico de varredura da calcita assinalada em 4A; C. Fotomicrografia dos agregados criptocristalinos de quartzo (QC) e dos agregados fibrosos orientados (CA) (LP, 25X). D. Detalhe dos agregados fibrosos de calcedônia (LP, 50X).

\subsection{Amostragem e métodos}

Amostras de ágata foram coletadas em diferentes geodos do derrame mineralizado do DMSJ e analisadas com o emprego de diversas técnicas: petrografia, difração de raios X, microscopia eletrônica de varredura, análises químicas e isotópicas. As amostras foram selecionadas em função dos diferentes bandamentos e colorações. Com o objetivo de comparar a ágata com o quartzo macrocristalino associado, algumas análises foram também realizadas em amostras deste polimorfo. Assim, foram confeccionadas lâminas petrográficas convencionais para a descrição e caracterização da textura e estrutura da ágata com auxílio de um microscópio petrográfico.

Fragmentos milimétricos do quartzo macrocristalino e dos diferentes bandamentos de ágata foram montados em suportes especiais, metalizados e observados ao microscópio eletrônico de varredura (MEV) em aumentos variados de até 5.000 vezes. Adicionalmente, para realização de análise de EDS (Espectômetro de energia dispersiva de raios $\mathrm{X}$ ) foi preparada uma lâmina petrográfica polida com uma seção da ágata associada ao quartzo macrocristalino com o objetivo de 
se obter uma composição química semi-quantitativa com o auxílio do EDS. O MEV utilizado foi um PHILIPS modelo XL30 com sistema EDS acoplado, pertencente ao Laboratório de Microscopia Eletrônica da Pontifícia Universidade Católica do Rio Grande do Sul.

Porções de ágata foram cuidadosamente retiradas dos geodos, pulverizadas e o material resultante foi quarteado. De uma alíquota representativa, foi separada a fração $<4 \mu \mathrm{m}$ para a confecção de lâminas naturais para análise por difração de raios X (DRX). Para a análise por DRX utilizou-se um difratômetro Siemens D5000 Diffraktometer com radiação $\mathrm{K} \alpha \mathrm{Cu}$ nas condições de $40 \mathrm{kV}$ e $30 \mathrm{~mA}$ de corrente de filamento e no intervalo de 2 a $28^{\circ}(2 \theta)$, pertencente ao Instituto de Geociências da Universidade Federal do Rio Grande do Sul. Os difratogramas obtidos permitiram a caracterização das fases silicosas presentes e também foram utilizados para a aplicação da equação de Scherrer (1918, apud Langford \& Wilson, 1978). Esta equação permite obter uma estimativa para dimensão do cristálito a partir da largura à meia altura do pico 002.

Amostras de ágata foram analisadas quimicamente para determinação dos elementos maiores, traços e terras raras. As análises foram realizadas no laboratório Acme Brazil Laboratório, pelos métodos de fluorescência de raios X e ICP-MS.

Outras alíquotas das duas fases (ágata e quartzo macrocristalino) foram analisadas para determinação das razões isotópicas de oxigênio $\left(\delta^{18} 0\right)$. As relações isotópicas de 0 constituem a principal técnica para a determinação da temperatura de formação da ágata. As composições isotópicas de oxigênio foram determinadas no Laboratório de Isótopos Estáveis do Departamento de Geologia da Universidade Federal de Pernambuco, em espectrômetro de massa VG Isotech SIRA II, usando o padrão interno BSC (Borborema skarn calcite). A linha de extração tem por base um laser de $\mathrm{CO}_{2}$, sendo o material preparado de acordo com os procedimentos descritos em Valley et al. (1995). Os resultados obtidos para as amostras de ágata do DMSJ estão expressos em \%o relativo ao padrão V-SMOW.

\section{Resultados}

As amostras de ágata analisadas provêm de geodos do DMSJ que apresentam variações nos preenchimentos e, de forma geral, quatro tipos principais são reconhecidos:

- totalmente preenchidos, onde se observa a alternância de uma camada espessa de ágata (até $6 \mathrm{~cm})$ com o quartzo macrocristalino $(2-3 \mathrm{~cm})$, que constituem a maior parte dos geodos encontrados na região. A ágata do tipo Umbu ocorre associada a este padrão de preenchimento;

- ocorrência menos abundante, onde uma camada milimétrica de ágata está na sua porção mais externa, seguida por uma camada mais espessa $(10-15 \mathrm{~cm})$ de quartzo macrocristalino, geral- mente com espaços vazios na porção central, o que faz com que este geodo tenha baixo valor comercial;

- contendo opala e raramente calcita, associados com ágata (Fig. 4B); e,

- preenchidos exclusivamente por ágata.

Há grande diversidade em termos de espessura das bandas e também da cor da ágata. A espessura das bandas pode variar de poucos milímetros até $2-3 \mathrm{~cm}$, enquanto a cor varia de banda para banda: cinza clara a cinza escura, branca a caramelo, e azul escura (ágata Umbu).

As bandas são caracterizadas individualmente por uma mudança gradual na cristalinidade e, consequentemente, mineralogia (diferentes polimorfos do quartzo) o que para Lee (2008) pode ser considerado como um processo análogo à diagênese da sílica. Isto pode ser observado microscopicamente, pois as bandas são constituídas, da borda para o centro dos geodos, por agregados criptocristalinos de quartzo, agregados fibrosos orientados (calcedônia) e quartzo microcristalino (Fig 4C). Os agregados fibrosos caracterizam-se pela orientação, pois os seus eixos principais ("a") são alongados, perpendiculares ao padrão de bandamento e orientados em direção ao centro dos geodos, conforme pode ser observado na figura 4D. 0 quartzo microcristalino apresenta uma textura granular, com grãos de dimensões inferiores a $20 \mu \mathrm{m}$ conforme critérios de Lee (2008). 0 quartzo macrocristalino pode ser considerado como uma fase posterior associada, quase sempre num último estágio de cristalização e com grãos cujas dimensões são bastante superiores ao limite estabelecido para o quartzo microcristalino.

Na figura 5, observa-se uma micrografia ao MEV juntamente com os dados composicionais obtidos com o EDS onde se verifica que há uma pequena diferença na composição química da ágata (AG) e do quartzo macrocristalino $(\mathrm{QM})$. Os cristais de quartzo macrocristalino desenvolvem-se como uma fase contínua da cristalização da ágata, sempre em direção à porção central dos geodos e se caracterizam pela ausência de impurezas ( $\mathrm{Al}, \mathrm{Fe}$ ), o que se verifica nas análises químicas efetuadas. Estas características levam a propor que sua cristalização ocorre a partir de soluções mais puras que aquelas contidas nos géis de sílica da qual a calcedônia fibrosa teria inicialmente se formado. Este comportamento também foi observado por Fischer (2004), que conclui que ocorre um decréscimo geral na concentração de elementos como $\mathrm{Al}$ e Fe, partindo-se da calcedônia (na parte mais externa do geodo) para o quartzo macrocristalino (no interior do geodo).

No entanto, são as diferenças texturais as mais marcantes (Fig. 5) pois, comprovando o observado na microscopia, verifica-se que a banda de ágata (calcedônia) apresenta uma superfície plana e homogênea, resultado das dimensões e orientação das fibras, enquanto o quartzo macrocristalino tem aspecto rugoso, refletindo a diferença textural entre as fases silicosas. 


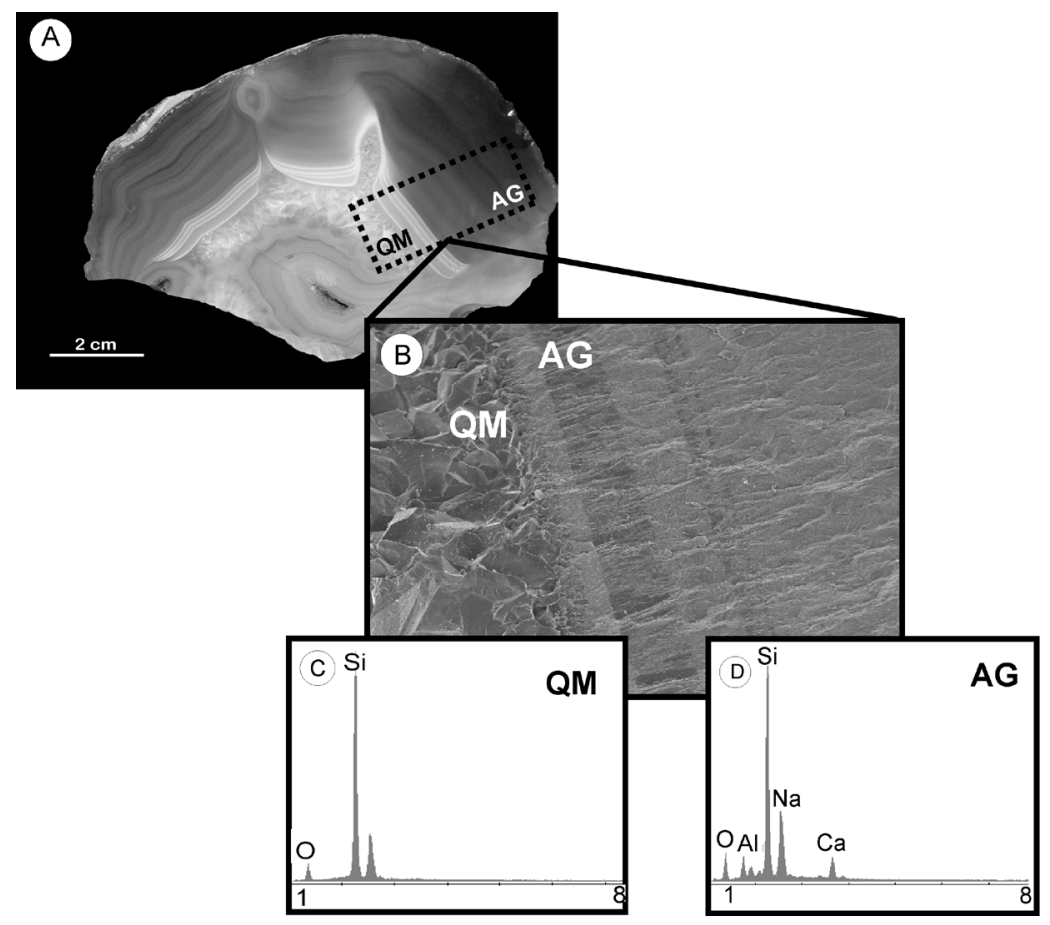

Figura 5. A. Fragmento de geodo mostrando as áreas analisadas; B. Fotomicrografia ao microscópio eletrônico de varredura destacando a transição entre a ágata (AG) e o quartzo macrocristalino (QM); observar a diferença textural marcante entre as fases; C. Resultado da análise ao espectômetro de energia dispersiva de raios X para o quartzo macrocristalino. D. Resultado da análise ao espectômetro de energia dispersiva de raios $\mathrm{X}$ para a ágata. ( $\mathrm{AG}=$ ágata e $\mathrm{QM}=$ quartzo macrocristalino).

Análises químicas de elementos maiores, traços e terras raras têm sido utilizados para o reconhecimento da geoquímica das ágatas e das suas condições de formação (Götze et al., 2001a; Lee, 2008). Contudo, análises químicas de ágatas coletadas em geodos associados com rochas vulcânicas são raras, e as suas interpretações são muito imprecisas (Flörke et al., 1982, Götze et al. 2001a; Merino et al., 1995).

Os resultados obtidos para as amostras de ágata

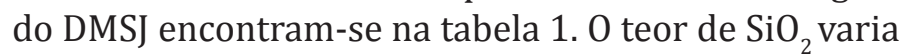
de 92,52 a 97,95 (\% peso), valores que de uma maneira geral são coerentes com o encontrado na literatura (Frondel, 1962; Paralı et al., 2011).

Marcantes são os valores de LOI (perda ao fogo) obtidos, que variam de 0,4 a 4,9\% peso. Amostras de ágata de procedências e idades distintas também apresentam variação considerável nos teores de LOI (Frondel, 1962; Hatipoğlu et al., 2011; Paralı et al., 2011). Além disso, as amostras de ágata dos diferentes geodos do DMSJ de uma maneira geral mostram variações significativas nos conteúdos de $\mathrm{Al}, \mathrm{Fe}, \mathrm{Cu}, \mathrm{Ni}$ e $\mathrm{Ba}$, entre outros elementos.

Outra particularidade, no caso das ágatas estudadas, é a correlação entre os teores de $\mathrm{SiO}_{2}$ e o LOI (Tab. 1) conforme a figura 6. Observa-se que as ágatas com menor teor em $\mathrm{SiO}_{2}$ apresentam não só os maiores valores para LOI, mas também as maiores concentrações de impurezas sob a forma de elementos maiores e traços conforme sugerido por Constantina \& Moxon (2010) e verificado nos resultados da tabela 1 (ver amostras 16, 3A e 3C). Este comportamento também ocorre nas amostras de ágata da Romênia, estudadas por Iancu et al. (2009).

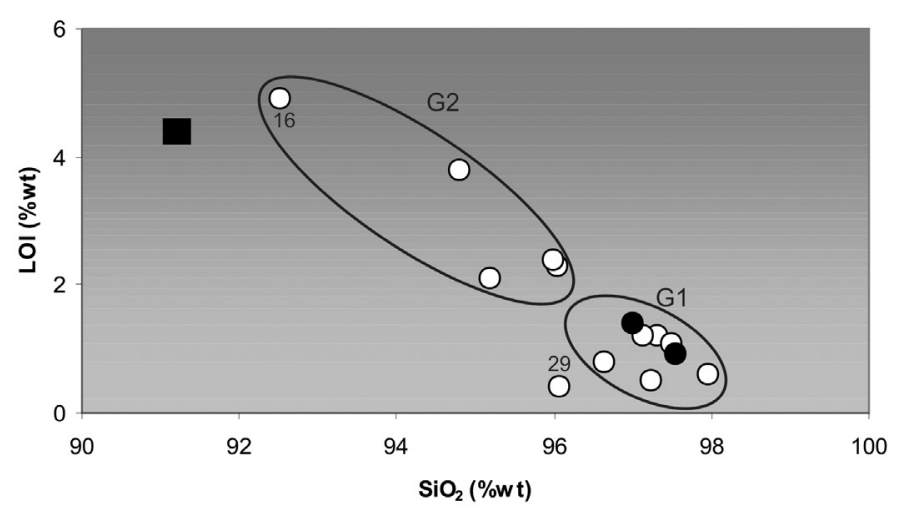

Figura 6. Diagrama $\mathrm{SiO}_{2}$ vs LOI para amostras de ágata do DMSJ (O: amostras do Distrito mineiro de salto do jacuí, este trabalho;círculos negros: resultados obtidos por Hatipoğlu et al. (2011); Círculos brancos: resultado obtido por Paralı et al. (2011). G1 - grupo de amostras de ágata com alta cristalinidade. G2 - grupo de amostras de ágata com baixa cristalinidade.

De uma forma geral, os valores para o $\mathrm{Fe}_{2} \mathrm{O}_{3}$ e para o $\mathrm{Al}_{2} \mathrm{O}_{3}$ nas amostras analisadas podem ser considerados como relativamente elevados quando comparados com os outros óxidos (Tab. 1). Merino et al. (1995) reportaram que a $\mathrm{Si}^{+4}$ pode ser substituída em diferentes graus e em diferentes sítios da ágata por elementos tais como o $\mathrm{Al}^{+3}$ e o $\mathrm{Fe}^{+3}$ nas fibras que estão se desenvolvendo. Consequentemente, há um déficit na carga, e os íons monovalentes como o $\mathrm{K}^{+1}$ e o $\mathrm{Na}^{+1}$ podem entrar na estrutura para compensar o balanço de carga. As amostras do DMSJ mostram que aos maiores teores relativos de $\mathrm{Al}_{2} \mathrm{O}_{3}$ também são associados os valores mais elevados de $\mathrm{K}_{2} \mathrm{O}$ e $\mathrm{Na}_{2} \mathrm{O}$, como por exemplo, a amostra 16 (ver Tab. 1).

Götze et al. (2001b) também propuseram que o 
teor de $\mathrm{Al}_{2} \mathrm{O}_{3}$ é um indicador da temperatura de formação da ágata embora outros autores (Moxon, 2002; Lee, 2008) não tenham observado esta associação. No caso das ágatas do DMSJ, somente a amostra 16 (Tab. 1) que apresenta o maior teor de $\mathrm{Al}_{2} \mathrm{O}_{3}$ e a menor temperatura de cristalização $\left(1,05 \%\right.$ peso e $23^{\circ} \mathrm{C}$, respectivamente) poderia indicar algum tipo de associação.

No entanto, em relação ao $\mathrm{Fe}_{2} \mathrm{O}_{3}$, se observa que este está relacionado ao pigmento da ágata, cujas proporções deste óxido originam diferentes tonalidades de ágata observadas (branco, diversos tons de cinza e azul escuro). Há uma correlação entre o teor de $\mathrm{Fe}_{2} \mathrm{O}_{3} \mathrm{e}$ a cor da ágata, ou seja, quanto mais escuro for o mineral, maior será a concentração de ferro. A amostra 16 tem cor branca, leitosa e o teor em Fe é relativamente baixo $(0,91 \%$ peso). Já a mostra 29 , com maior teor em Fe $(3,44 \%$ peso), tem cor azul escura, caracterizando a chamada ágata Umbu do DMSJ. Na realidade, este elemento é bem conhecido e descrito como pigmento em diferentes variedades de minerais silicosos como a calcedônia, ágata e opala (Hatipoğlu et al., 2011).

Outra diferença marcante entre as amostras 16 e 29 pode ser observada nas análises por difração de raios X (Fig. 7). A amostra 16 apresenta um pico indicativo da presença de cristobalita associada com a ágata. A cristobalita, no entanto, não ocorre na amostra 29, que é uma ágata "pura" (Fig. 7). A cristobalita, polimorfo de alta temperatura da sílica, foi interpretada como uma fase ainda associada ao vulcanismo, esta amostra caracteriza-se pela presença de impurezas como $\mathrm{Al}$ e Ca na sua estrutura.

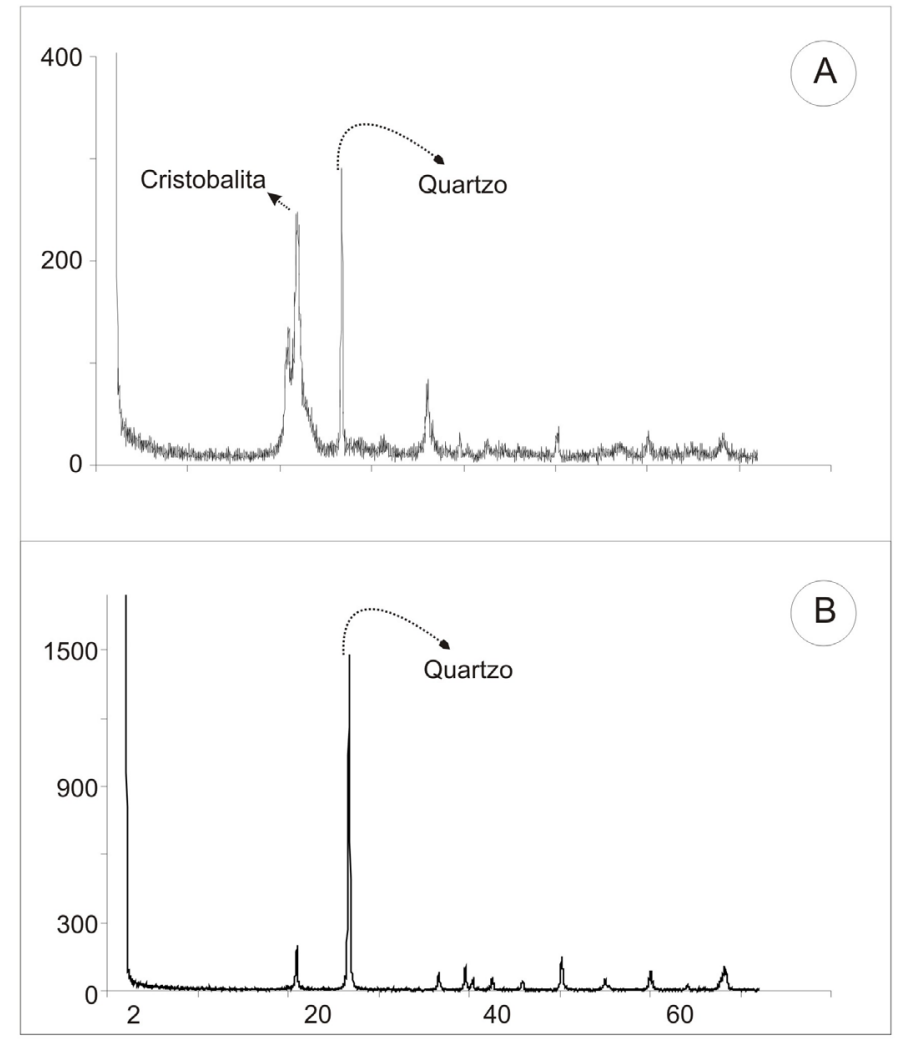

Figura 7. Padrões de difração de raios X para: A. Amostra 16; B. Amostra 29 (ágata Umbu).

Nas amostras de ágata do DMSJ, aplicou-se a equa- ção de Scherrer com o objetivo de verificar a diferença em termos de tamanho de cristais e fibras. Os valores encontrados variam de 37 a $60 \mathrm{~nm}$ (Tab. 2) e foram interpretados como correspondendo ao diâmetro médio das partículas individuais $\left(\mathrm{C}_{\mathrm{s}(101)}\right)$, refletindo a diferença na cristalinidade observada nas bandas. Seguindo o modelo proposto por Constantina \& Moxon (2010) para a diferenciação do grau de cristalinidade da ágata, com base nestes valores, optou-se por considerar dois grupos distintos:

- com valores de $60 \mathrm{~nm}$, indicando alta cristalinidade;

- com valores entre 29-45 $\mathrm{nm}$, considerados como indicativos de baixa-média cristalinidade.

Constatou-se que no grupo com valores indicativos de alta cristalinidade, os valores de LOI são inferiores e o teor de sílica é mais elevado (médias entre 0,6-1,1\% peso e $97-98 \%$ peso, respectivamente). No grupo considerado de baixa-média cristalinidade, os valores de LOI estão entre 1,2-4,9\% e os valores de $\mathrm{SiO}_{2}$ variam de 92 a 97\%. Pode-se observar este comportamento em todos os exemplares de ágata analisados, com exceção da amostra 29 (ver tab. 1), cujo teor de LOI está muito abaixo do padrão que se observa nas demais. Esta amostra corresponde à ágata Umbu com comportamento geoquímico diferenciado, pois além de ter elevada concentração de $\mathrm{Fe}_{2} \mathrm{O}_{3}(3,44 \%$ peso), o somatório dos elementos traço $\mathrm{Ni}$, Co e $\mathrm{Cu}$ apresenta valor relativamente elevado $(19,8 \%)$ (ver tab. 1). Isto pode ser interpretado como elementos presentes em micro-inclusões da ágata, responsáveis pela coloração mais escura.

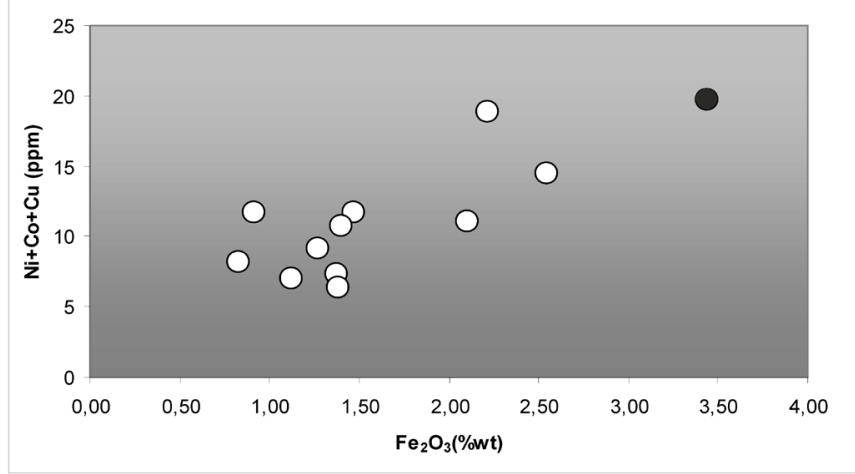

Figura 8. Diagrama $\mathrm{Fe}_{2} \mathrm{O}_{3}(\%$ em peso) vs $(\mathrm{Ni}+\mathrm{Co}+\mathrm{Cu})(\mathrm{ppm})$ para as amostras de ágata do DMSJ. Círculo negro preenchido - Amostra 29 (ágata Umbu). Círculo sem preenchimento - demais amostras de ágata do DMSJ.

Ao observar os elementos menores, percebe-se que o urânio se destaca por apresentar teores mais elevados, se comparado a outros elementos, além de uma ampla variação entre as amostras $(0,1$ a 7,3 ppm) (Tab 1). Os teores de U, quando comparados ao Th (sempre abaixo do limite de detecção $<0,2$ ), podem ser considerados como elevados e podem indicar transporte e acumulação por fluidos devido à mobilidade do íon uranila. $\mathrm{O}$ U não é incorporado na estrutura da ágata e provavelmente encontra-se associado com micro-in- 
Tabela 1. Análises químicas das amostras de ágata do DMSJ (elementos maiores em \% em peso, elementos traços em ppm; n.d.=abaixo do limite de deteç̧ão do equipamento utilizado).

\begin{tabular}{|c|c|c|c|c|c|c|c|c|c|c|c|c|}
\hline & $3 \mathrm{~A}$ & $3 C$ & 16 & 29 & 33 & 56 & 57 & 60 & 65 & 66 & 67 & 70 \\
\hline $\mathrm{SiO}_{2}$ & 95,17 & 94,80 & 92,52 & 96,06 & 97,95 & 97,24 & 96,62 & 97,31 & 96,04 & 95,99 & 97,48 & 97,13 \\
\hline $\mathrm{Al}_{2} \mathrm{O}_{3}$ & 0,34 & 0,21 & 1,05 & 0,05 & 0,06 & 0,11 & 0,04 & 0,04 & 0,07 & 0,47 & 0,03 & 0,18 \\
\hline $\mathrm{Fe}_{2} \mathrm{O}_{3}$ & 2,21 & 1,12 & 0,91 & 3,44 & 1,37 & 2,10 & 2,54 & 1,27 & 1,47 & 0,82 & 1,38 & 1,40 \\
\hline MgO & 0,04 & 0,03 & 0,15 & n.d. & n.d. & n.d. & n.d. & n.d. & n.d. & 0,03 & n.d. & 0,02 \\
\hline $\mathrm{CaO}$ & 0,02 & n.d. & 0,24 & n.d. & 0,02 & 0,03 & n.d. & 0,02 & 0,03 & 0,15 & 0,02 & 0,05 \\
\hline $\mathrm{Na}_{2} \mathrm{O}$ & 0,04 & 0,04 & 0,04 & 0,02 & 0,02 & 0,03 & 0,02 & 0,02 & 0,01 & 0,09 & 0,02 & 0,04 \\
\hline $\mathrm{K}_{2} \mathrm{O}$ & 0,09 & 0,03 & 0,12 & n.d. & 0,01 & 0,03 & 0,01 & 0,01 & 0,02 & n.d. & n.d. & n.d. \\
\hline $\mathrm{TiO}_{2}$ & n.d. & n.d. & n.d. & n.d. & n.d. & n.d. & n.d. & n.d. & n.d. & n.d. & n.d. & n.d. \\
\hline $\mathrm{P}_{2} \mathrm{O}_{5}$ & n.d. & n.d. & 0,02 & 0,02 & n.d. & 0,01 & n.d. & 0,03 & n.d. & n.d. & n.d. & 0,01 \\
\hline $\mathrm{MnO}$ & 0,02 & 0,01 & 0,04 & 0,04 & 0,02 & 0,02 & 0,03 & 0,04 & 0,02 & 0,03 & 0,02 & 0,02 \\
\hline $\mathrm{Cr}_{2} \mathrm{O}_{3}$ & n.d. & n.d. & n.d. & n.d. & 0,004 & n.d. & 0,003 & n.d. & n.d. & n.d. & n.d. & n.d. \\
\hline $\begin{array}{l}\text { LOI } \\
\text { Total }\end{array}$ & $\begin{array}{c}2,1 \\
100,03\end{array}$ & $\begin{array}{c}3,8 \\
100,04\end{array}$ & $\begin{array}{c}4,9 \\
100,03\end{array}$ & $\begin{array}{c}0,4 \\
100,03\end{array}$ & $\begin{array}{c}0,6 \\
100,08\end{array}$ & $\begin{array}{c}0,5 \\
100,06\end{array}$ & $\begin{array}{c}0,8 \\
100,06\end{array}$ & $\begin{array}{c}1,2 \\
99,99\end{array}$ & $\begin{array}{c}2,3 \\
100,01\end{array}$ & $\begin{array}{c}2,4 \\
99,98\end{array}$ & $\begin{array}{c}1,1 \\
100,06\end{array}$ & $\begin{array}{c}1,2 \\
100,05\end{array}$ \\
\hline $\mathrm{Cu}$ & 13,5 & 5,1 & 9,7 & 12,4 & 4,7 & 7,1 & 9,5 & 6,6 & 7,5 & 4,8 & 4,3 & 7,1 \\
\hline $\mathrm{Pb}$ & 0,5 & 0,1 & 0,2 & n.d. & n.d. & 0,8 & n.d. & n.d. & 0,4 & 0,6 & n.d. & 0,9 \\
\hline $\mathrm{Ni}$ & 4,3 & 1,5 & 1,3 & 5,5 & 1,9 & 3,1 & 4,0 & 2,0 & 3,2 & 2,5 & 1,7 & 2,8 \\
\hline As & 1,5 & 1,0 & 0,6 & 1,5 & 0,5 & 0,9 & 0,9 & 0,8 & 0,8 & n.d. & 0,5 & 0,6 \\
\hline $\mathrm{Ba}$ & 56 & 7 & 91 & 5 & 2 & 8 & n.d. & 58 & 20 & 85 & 2 & 65 \\
\hline Co & 1,1 & 0,5 & 0,7 & 1,9 & 0,8 & 0,9 & 1,0 & 0,6 & 1,0 & 0,9 & 0,4 & 0,9 \\
\hline $\mathrm{Ga}$ & 1,7 & 1,8 & 1,8 & 1,0 & 1,3 & 1,9 & 0,8 & 2,3 & 0,9 & 1,3 & 1,9 & 1,5 \\
\hline $\mathrm{Nb}$ & 0,3 & 0,2 & n.d. & n.d. & 0,6 & 0,5 & n.d. & 0,2 & 0,1 & 0,1 & n.d. & 0,1 \\
\hline $\mathrm{Rb}$ & 7,2 & 3,3 & 15,9 & 0,2 & 0,2 & 1,5 & 0,3 & 0,7 & 0,8 & 0,6 & 0,3 & 0,5 \\
\hline $\mathrm{Sr}$ & 24,4 & 7,2 & 21,7 & 1,2 & 0,5 & 2,7 & 0,6 & 6,2 & 1,6 & 13,1 & 0,6 & 23,2 \\
\hline Th & n.d. & n.d. & n.d. & n.d. & n.d. & 0,3 & n.d. & n.d. & n.d. & n.d. & n.d. & n.d. \\
\hline $\mathrm{U}$ & 3,2 & 7,3 & n.d. & 1,2 & n.d. & n.d. & 0,5 & 4,6 & 0,3 & 3,7 & n.d. & 2,3 \\
\hline $\mathrm{Zr}$ & 1,9 & 0,8 & 0,9 & 0,6 & 0,9 & 3,4 & 0,5 & 2,3 & 1,7 & 12,9 & 0,2 & 2,7 \\
\hline Y & 3,9 & 0,6 & 0,8 & 0,1 & 0,2 & 0,5 & 0,9 & 0,7 & 0,2 & 0,2 & 0,2 & 0,6 \\
\hline $\mathrm{La}$ & 0,2 & n.d. & 0,2 & n.d. & 0,2 & 0,9 & n.d. & 0,2 & 0,3 & 0,4 & n.d. & 0,1 \\
\hline $\mathrm{Ce}$ & 0,9 & 0,5 & 0,3 & n.d. & n.d. & 2,0 & n.d. & 0,2 & 0,6 & 1,4 & n.d. & 0,3 \\
\hline $\operatorname{Pr}$ & 0,11 & 0,06 & n.d. & n.d. & n.d. & 0,20 & n.d. & 0,03 & 0,04 & 0,04 & n.d. & 0,05 \\
\hline $\mathrm{Nd}$ & 0,5 & n.d. & n.d. & n.d. & n.d. & 0,7 & n.d. & n.d. & n.d. & n.d. & n.d. & n.d. \\
\hline $\mathrm{Sm}$ & 0,09 & 0,06 & n.d. & n.d. & n.d. & 0,12 & n.d. & n.d. & n.d. & n.d. & n.d. & 0,05 \\
\hline $\mathrm{Eu}$ & n.d. & n.d. & n.d. & n.d. & n.d. & 0,02 & n.d. & n.d. & n.d. & n.d. & n.d. & n.d. \\
\hline $\mathrm{Gd}$ & 0,10 & n.d. & n.d. & n.d. & n.d. & 0,08 & n.d. & n.d. & n.d. & n.d. & n.d. & n.d. \\
\hline $\mathrm{Tb}$ & 0,03 & n.d. & n.d. & n.d. & n.d. & 0,01 & 0,04 & n.d. & n.d. & n.d. & 0,03 & n.d. \\
\hline Dy & 0,27 & 0,07 & 0,08 & n.d. & n.d. & 0,06 & 0,07 & 0,06 & n.d. & n.d. & n.d. & n.d. \\
\hline Ho & 0,09 & n.d. & n.d. & n.d. & 0,03 & n.d. & n.d. & n.d. & n.d. & n.d. & n.d. & n.d. \\
\hline Er & 0,31 & 0,07 & n.d. & n.d. & 0,05 & 0,04 & 0,08 & n.d. & n.d. & n.d. & n.d. & 0,04 \\
\hline $\mathrm{Tm}$ & 0,07 & 0,01 & 0,01 & n.d. & n.d. & n.d. & 0,05 & n.d. & n.d. & n.d. & n.d. & n.d. \\
\hline $\mathrm{Yb}$ & 0,47 & 0,10 & 0,08 & n.d. & n.d. & n.d. & 0,10 & 0,05 & n.d. & n.d. & n.d. & 0,06 \\
\hline $\mathrm{Lu}$ & 0,07 & 0,02 & 0,01 & n.d. & n.d. & n.d. & 0,01 & n.d. & n.d. & n.d. & n.d. & n.d. \\
\hline
\end{tabular}

Tabela 2. Resultados da aplicação da Equação de Scherrer (1918, apud Langford \& Wilson, 1978) nas amostras de ágata do DMSJ (FWHM $(\beta)=$ medida da largura do pico de difração a meia altura; $\mathrm{C}_{\mathrm{s}(101)}=$ diâmetro médio das partículas individuais).

\begin{tabular}{ccc}
\hline Amostra & FWHM $(\boldsymbol{\beta})$ & $\mathbf{C}_{\mathbf{s}(101)} \mathbf{n n}$ \\
$3 \mathrm{~A}$ & $0,29^{\circ}$ & 29 \\
65 & $0,23^{\circ} \mathrm{o}$ & 37 \\
60 & $0,20^{\circ}$ & 42 \\
29 & $0,20^{\circ} \mathrm{o}$ & 42 \\
16 & $0,19^{\circ}$ & 44 \\
67 & $0,14^{\circ}$ & 60 \\
57 & $0,14^{\circ}$ & 60 \\
33 & $0,14^{\circ}$ & 60 \\
\hline
\end{tabular}


clusões ou adsorvido sob forma de complexos (Götze et al., 2001b).

Lee (2008) destacou que a água presente em minerais silicosos pode ser dependente do grau de cristalinidade do polimorfo ou das impurezas presentes no sistema. $\mathrm{O}$ autor considera que o decréscimo do teor de água pode ocorrer devido à redução da área superficial como consequência do aumento da ordenação estrutural e da dimensão do cristal. Outra possibilidade é que o conteúdo de água decresce, porque esta não pode mais ser acomodada na estrutura do mineral devido à inclusão de outras impurezas, que possivelmente é o caso da amostra de ágata 29 do DMSJ.

Como as amostras analisadas apresentam características composicionais e texturais marcantes e diferenciais (por exemplo, amostras 16 e 29), foram realizadas determinações de temperatura com base na assinatura isotópica de 0 para as diferentes fases de preenchimento (ágata e quartzo macrocristalino). Os valores variam de 24,0 a 30,51 \%o (Tab. 3). A inferência da temperatura de cristalização foi obtida através da equação proposta por Clayton et al. (1972), e os resultados estão expressos na tabela 3. 0 parâmetro necessário para o cálculo da temperatura é o valor previsto para a composição isotópica do fluido responsável pela mineralização. Em trabalhos anteriormente realizados em mineralizações da Bacia do Paraná para fins de cálculo de temperatura, tradicionalmente tem-se utilizado o valor -5\%o (Junchem, 1999; Duarte, 2008). Este valor corresponde à assinatura isotópica atual para a água do Rio Jacuí do DMSJ (Fig. 1) proposto por Matzui et al. (1974). Adicionalmente, foi realizado o cálculo com outros valores para fins de comparação, água meteórica com composição isotópica de $-10 \%$ (valor inferido para águas meteóricas de maior latitude) e + $8 \%$, valor considerado para um fluido magmático, assim como Götze et al. (2009). Com base nos resultados (Tab. 6), foram consideradas as temperaturas obtidas com o valor de $-5 \%$ como o mais provável. Com base neste valor, a temperatura de cristalização da ágata do DMSJ varia de $23^{\circ}$ a $65^{\circ} \mathrm{C}$, valores relativamente baixos. Os resultados com o valor de $-10 \%$ o $\left(6^{\circ}\right.$ a $39^{\circ} \mathrm{C}$, Tab.
6) são muito inferiores e considerados inviáveis, e o de $8 \%$ o $\left(91^{\circ}\right.$ a $\left.178^{\circ} \mathrm{C}\right)$, ao contrário, resulta em valores muito elevados em relação ao que tem sido proposto na literatura (Fallick et al., 1985; Landmesser, 1988; Harris, 1989). A temperatura de $23^{\circ} \mathrm{C}$ é muito baixa, superficial, porém valores similares foram obtidos Götze et al. (2001b). Estes autores também utilizaram isótopos de oxigênio para o cálculo da temperatura e analisou ágatas da Namíbia coletadas em ambiente vulcânico análogo ao DMSJ.

Ao observar os valores obtidos para o intervalo de temperaturas entre $23^{\circ}$ e $65^{\circ} \mathrm{C}$, verifica-se uma correlação interessante, pois, aos maiores valores de temperatura correspondem as amostras com maior teor de $\mathrm{SiO}_{2}$ e menor valor de LOI. Também há uma relação com os valores para o óxido de ferro $(0,82$ a $3,44 \%$ peso); maiores teores de $\mathrm{Fe}_{2} \mathrm{O}_{3}$ estão associadas às maiores temperaturas de cristalização. Além disso, mudanças na coloração da ágata também são observadas, ou seja, nas amostras de coloração azul escura, os teores de $\mathrm{Fe}_{2} \mathrm{O}_{3}$ são mais elevados, conforme anteriormente citado.

Com o objetivo de comparar as temperaturas de cristalização da ágata e da fase de quartzo macrocristalino, foram realizadas análises de isótopos estáveis de 0 em três amostras desta última fase. A composição isotópica do quartzo macrocristalino varia de $+24,00$ a $+22,25 \%$ o (Tab. 3). Calculando a temperatura com base neste parâmetro, obtiveram-se temperaturas de 50 e $51^{\circ} \mathrm{C}$, compatíveis com o intervalo obtido para as amostras de ágata $\left(23^{\circ}\right.$ a $\left.65^{\circ} \mathrm{C}\right)$.

A amostra 16, além de ter baixa temperatura de cristalização $\left(23^{\circ} \mathrm{C}\right)$ e relativamente alto teor de $\mathrm{Al}_{2} \mathrm{O}_{3}$ (Tab. 1), apresenta concentrações mais elevadas de Ba, $\mathrm{Rb}, \mathrm{Sr}, \mathrm{CaO}$ e $\mathrm{K}_{2} \mathrm{O}$. Estes altos teores confirmam a presença de carbonatos associados, conforme observado não só macroscopicamente como também ao microscópio eletrônico de varredura.

Para as amostras de ágata analisadas do DMSJ, os resultados de elementos terras raras apresentam concentrações extremamente baixas, em sua maioria abaixo do limite de detecção (tab. 1). Isto contrasta

Tabela 3. Resultados do cálculo de temperatura com base na relação isotópica do oxigênio nos cristais de quartzo macrocristalino e ágata $(\mathrm{MQ}$ = quartzo macrocristalino, $\mathrm{AG}$ = ágata $)$.

\begin{tabular}{|c|c|c|c|c|c|}
\hline Amostra & Mineral & $\delta^{18} \mathbf{O}_{\text {smow }(\%)}$ & To C Água meteórica (-5\%) & To C Água meteórica (-10\%o) & Tº C Água magmática (8\%o) \\
\hline $31 \mathrm{~A}$ & QM & 24,25 & 50 & 28 & 144 \\
\hline $13 \mathrm{~A}$ & $\mathrm{QM}$ & 24,00 & 51 & 29 & 147 \\
\hline $22 \mathrm{~A}$ & QM & 24,01 & 51 & 29 & 147 \\
\hline 16 & $\mathrm{AG}$ & 30,51 & 23 & 6 & 91 \\
\hline $32 \mathrm{C}$ & $\mathrm{AG}$ & 26,38 & 40 & 20 & 124 \\
\hline 23 & $\mathrm{AG}$ & 26,50 & 40 & 19 & 123 \\
\hline $32 B$ & $\mathrm{AG}$ & 25,60 & 44 & 22 & 131 \\
\hline 33 & $\mathrm{AG}$ & 24,08 & 51 & 28 & 146 \\
\hline 29 & $\mathrm{AG}$ & 21,41 & 65 & 39 & 178 \\
\hline
\end{tabular}


com outros estudos em que os elementos terras raras apresentaram uma concentração razoável, permitindo inclusive a sua normalização (Götze et al., 2001b). Nas ágatas do DMSJ, em raras amostras, somente é possível verificar que o somatório dos ETR leves ( $\Sigma E T R L)$ é superior ao somatório dos ETR pesados ( $E$ ETRP). Morgan \& Wandless (1980) mostraram que os ETR leves tendem a substituir os cátions maiores, como o $\mathrm{Ca}^{2+} \mathrm{e}$ o $\mathrm{Ba}^{2+}$. De uma forma muito geral pode-se ver que as amostras com maior teor de ETR leves também apresentam os maiores valores para $\mathrm{Ba}^{+2}$ (ver tab. 1).

\section{Conclusões}

Nas amostras de ágata da região do DMSJ são reconhecidas bandas formadas por agregados criptocristalinos de quartzo, agregados fibrosos orientados (calcedônia) e quartzo microcristalino sempre se dispondo da parede do geodo para o seu interior. As fibras da calcedônia são alongadas perpendicularmente ao eixo " $\mathrm{C}$ ”, porém periodicamente sofrem torção ao redor deste eixo, o que provavelmente origina a extinção ondulante observada ao longo das fibras. As camadas menos espessas de quartzo cripto- a microcristalino intercalam-se com a estrutura fibrosa da calcedônia originando a estrutura bandada típica. As fibras de calcedônia são recobertas por cristais anédricos de quartzo cujas dimensões vão aumentando em direção às porções mais centrais do geodo. De uma forma geral, pode se dizer que as dimensões dos cristais de quartzo aumentam, porém, a quantidade de cristais decresce, ou seja, identifica-se o quartzo macrocristalino predominante na porção mais interna dos geodos.

Outra característica importante das ágatas é a microporosidade que está associada à presença de água na sua estrutura, visualizada nos valores de LOI que são variáveis $(0,4$ a 4,9\% em peso). Isto também se reflete na química, pois quanto mais pura a ágata, menor é a quantidade de água incorporada pelo sistema, mais raramente são observadas impurezas quanto maior é a cristalinidade apresentada.

Dentre as impurezas mais comuns está o $\mathrm{Al}_{2} \mathrm{O}_{3}$, óxido que apresenta maior concentração depois da $\mathrm{SiO}_{2}$, e sempre está acompanhado por um aumento relativo dos teores de $\mathrm{Na}, \mathrm{K}$, e Rb. Esta associação reflete a substituição do $\mathrm{Si}^{+4}$ pelo $\mathrm{Al}^{+3}$ e consequente desequilíbrio de carga, tornando necessária a incorporação de um cátion de valência +1 na estrutura.

$\mathrm{O} \mathrm{Fe}_{2} \mathrm{O}_{3}$, outra impureza, está relacionado com a pigmentação da ágata, pois as amostras cuja coloração é mais escura (como a ágata Umbu) têm uma concentração maior deste óxido. Em contrapartida, nas amostras mais claras (como a amostra 16, de cor branca) a concentração é mais baixa.

As temperaturas obtidas para a formação da ágata do DMSJ são consistentes com dados de outros autores (Juchem, 1999; Gilg et al., 2003) indicando valores entre $23^{0}$ e $65^{\circ} \mathrm{C}$ e sendo caracterizadas como hidrotermais.
Verifica-se assim que as amostras analisadas caracterizam-se por diferenças marcantes nos teores de elementos maiores e traços, na temperatura de cristalização e na cristalinidade, o que indica que, mesmo se tratando de ágatas provenientes de uma mesma região, ocorrem variações no seu processo de cristalização. Isto resulta nas diferentes estruturas e colorações que são apresentadas pelas ágatas do DMSJ. Verifica-se que o comportamento da cristalização dos minerais silicosos que preenchem os geodos é complexo, havendo necessidade de estudos mais detalhados, incluindo também o conhecimento sobre a fonte da sílica responsável pela mineralização.

Agradecimentos - A primeira autora agradece ao Conselho Nacional de Desenvolvimento Científico e Tecnológico - CNPq pela bolsa de doutorado concedida (Processo CNPq 142685/2007-0). Agradecemos a Milton Formoso pelas sugestões que muito aprimoraram este trabalho e a Guilherme Tambara (bolsista de iniciação científica da FAPERGS) pela colaboração no trabalho de campo.

\section{Referências}

Bossi, J. \& Caggiano, W. 1974. Contribuición a la geologia de los yacimentos de amatista del Departamento de artigas (Uruguay). In: CONGRESSO BRASILEIRO DE GEOLOGIA, 28, 1974, Porto Alegre. Anais... Porto Alegre, SBG, v.3, P. 301-318.

Brum, T.M.M., Juchem, P.L., Agostini, I.M. \& Fiorentini, J.A. 1998. Classificação da ágata. In: Departamento Nacional da Produção Mineral. Ágata do Rio Grande do Sul. Brasilia, v. 1, p. 37-63

Clayton, R.N., O’Neil, J.R., Mayeda, T.K. 1972. Oxigen isotope exchange between quartz and water. Journal of Geophysical Research, 77: 3057-3067.

Constantina, C. \& Moxon, T. 2010. Agates from Gurasada, southern Apuseni Mountains Romenia: an XRD and termogravimetric study. Carpathian Journal of Earth and Environmental Sciences, 5 (02): 89-99.

Duarte, L.C. 2008. Evolução geológica, geoquímica e isotópica das mineralizações de geodos com ametista, Artigas, República Oriental do Uruguai. Porto Alegre, 167p. Tese de Doutorado, Programa de Pós-graduação em Geociências, Instituto de Geociências, Universidade Federal do Rio Grande do Sul.

Fallick, A.E., Jocelyn, J., Donnelly, T., Guy, M. \& Behan, C. 1985. Origin of agates in volcanic rocks from Scotland. Nature, 313: 672-674.

Fischer, A.C. 2004. Petrografia e geoquímica das fases silicosas dos geodos mineralizados a ametista (Região do Alto Uruguai, RS, Brasil). Porto Alegre, 159p. Tese de Doutorado, Programa de Pós-graduação em Geociências, Instituto de Geociências, Universidade Federal do Rio Grande do Sul.

Flörke O.H., Köhler-Herbertz B., Lamger, K \& Tönges, I. 1982. Water in microcrystalline quartz of volcanic origin: agates. Contribution to Mineral Petrology, 80: 324-333.

Frondel, C.1962. The system of mineralogy of Dana, J. D. 7th. ed. New York: John Wiley, 334p.

Gilg,H.A., Morteani,G., Kostitsyn Y., Gatter, I. \& Strieder, A.J. 2003. Genesis of amethyst geodes in basaltic rocks of the Serra Geral formation (Ametista do Sul, Rio Grande do 
Sul, Brazil): a fluid inclusion, REE, oxygen, carbon, and $\mathrm{Sr}$ isotope study on basalt, quartz, and calcite. Mineralium Deposita, 38(8):1009-1025.

Götze, J., Plötze, M., Tichomirowa, M., Fuchs, H. \& Pilot, J. 2001a. Aluminium in quartz as an indicator of the temperature of formation of agate. Mineralogical Magazine, 65(3): 407-413.

Götze, J., Tichomirowa, M., Fuchs, H., Pilot, J. \& Sharp, Z. D. 2001b. Geochemistry of Agates: A Trace Element and Stable Isotope Study: Chemical Geology, 175: 523-541.

Götze, J., Plötze, M., Fuchs, H. \& Habermann, D. 2009. Defect Structure and Luminescence Behaviour of Agate - Results of Electron Paramagnetic Resonance (EPR) and Cathodoluminescence (CL) Studies. Mineralogical Magazine, 63(2): 149-163.

Harris, C. 1989. Oxygen-isotope zonation of agates from Karoo volcanics of the Skeleton Coast, Namíbia. American Mineralogist, 74: 476-481.

Hatipoğlu, M., David, Ajò \& Kırıkoğlu, M.S. 2011. Cathodoluminescence (CL) features of the Anatolian agates, hydrothermally deposited in different volcanic hosts from Turkey. Journal of Luminescence, 131: 1131-1139.

Heemann, R. 1997. Geologia, controles e guias prospectivos para depósitos de ágata na região de Salto do Jacuí. Porto Alegre, 127 p. Dissertação de Mestrado, Programa de Pós-graduação em Engenharia de Minas, Metalurgia e dos Materiais, Escola de Engenharia, Universidade Federal do Rio Grande do Sul.

Heemann R. 2005. Modelagem estrutural e tridimensional para a prospecção e avaliação dos depósitos de ágata do distrito mineiro de Salto do Jacuí (RS). Porto Alegre, 150 p. Tese de Doutorado, Programa de Pós-graduação em Engenharia de Minas, Metalúrgica e de Materiais, Escola de Engenharia, Universidade Federal do Rio Grande do Sul.

Hurlbut Jr., C. S. \& Switzer G.S. 1980. Gemologia. Barcelona, Editora Omega, S.A. 251p.

Iancu, O.G, Toda, D.P. \& Iancu, G. 2009. Mineral chemistry of some agates from Gurasada (Mureş Valley, Romania) Studia Universitatis Babeş-Bolyai. Geology, 54 (1): 37 - 41.

Juchem, P.L. 1999. Mineralogia, geologia e gênese dos depósitos de ametista da Região do Alto Uruguai, Rio Grande do Sul. São Paulo, 225 p. Tese de doutorado, Programa Pós-graduação em Geociências, Universidade de São Paulo.

Landmesser, M. 1988. Structural characteristics of agates and their genetic significance. Neus Jardbuch Mineralogie, Abh 159: 223-235.

Langford J.I. \& Wilson, A.J.C. 1978. Scherrer after Sixty Years: A Survey and Some New Results in the Determination of Crystallite Size. Journal applied Crysallography, 11: 102113.

Lee, D. R., 2008. Characterisation of silica minerals in a banded agate: implications for agate genesis and growth mechanisms. Disponível em: http://www.geos.ed.ac.uk/ homes/50789516/agate.pdf. Acessado em: 21 ago. 2011.

Matzui, E., Salati, E., \& Marini, O. J. 1974. D/H and ${ }^{18} \mathrm{O} /{ }^{16} \mathrm{O}$

Manuscrito 485

Editores: Maria de Fatima Bitencourt e Paulo A. Souza. ratios in waters contained in geodes from the Basaltic Province of Rio Grande do Sul, Brazil. Geological Society American Bulletin, 85: 577-580.

Melfi, A.J., Piccirillo, E.M. \& Nardy, A.J.R. 1988. Geological and magmatic aspects of the Paraná Basin - an introduction. ln: Piccirillo E.M. \& Melfi, A.J. (Eds.). The Mesozoic flood volcanism of the Paraná Basin: petrogenetic and geophisycal aspects. São Paulo, Universidade de São Paulo, p. 1-13.

Merino, E., Wang, Y. \& Deloule, E. 1995. Genesis of agates in flood basalts: twisting of chalcedony fibers and trace - elements geochemistry. American Journal of Science, 295: 1156-1176.

Milani, E.J. 1997. Evolução Tectono- Estratigráfica da Bacia do Paraná e seu Relacionamento com a Geodinâmica Fanerozóica do Gondwana Sul-Ocidental. 255 p. Tese de Doutorado, Programa de Pós-graduação em Geociências, Instituto de Geociências, Universidade Federal do Rio Grande do Sul.

Morgan, J.W. \& Wandless, G.A.. 1980. Rare earth element distribution in some hydrotermal minerals: evidence for crystallographic control. Geochimica et Cosmochimica Acta, 44: 973-980.

Moxon,T. 2002. Agate: a study of ageing. European Journal Minerology, 14: 1109 - 1118.

Parall, L., Garcia Guinea, J., Kibar, R., Cetin, A. \& Can, N. 2011. Luminescence behaviour and Raman characterization of dendritic agate in the Dereyalak village (Eskişehir), Turkey. Journal of Luminescence, 131(11): 2317-2324.

Peate, D.W, Hawkesworth, C.J. \& Mantovani, M.S.M. 1992. Chemical stratigraphy of the Paraná lavas (South America): classification of magma types and their spatial distribution. Bulletin of Volcanology, 55:119-139.

Piccirillo, E.M., Melfi, A.J., Comin-Chiaramonti, P., Bellieni, G., Ernesto, M., Marques, L.S., Nardy, A.J.R., Pacca, I.G., Roisenberg, A. \& Stolfa, D. 1988. In: Piccirillo E.M. \& Melfi, A.J. (Eds.) Continental flood volcanism from the Paraná Basin (Brazil), Continental flood basalts, p. 195-238.

Renne, P.R., Ernesto, M., Pacca, I.G., Coe, R.S., Glen, J., Prevot, M., \& Perrin, M. 1992. The age of e Paraná flood vulcanism, rifting of Gondwanaland, and the Jurassic-Cretaceous boundary. Science, 258: 975-979.

Scherer C.M. 2000. Eolian Dunes of the Botucatu Formation (Cretaceous) in Southermost Brasil: morphology and origin. Sedimentary Geology, 137: 63-84.

Strieder, A.J. \& Heemann, R. 2006. Structural constraints on Paraná basalt volcanism and their implications on agate geode mineralization (Salto do Jacuí, RS, Brazil). Pesquisas em Geociências, 33(1): 37-50.

Valley J.W., Kitchen N, Kohn M.J., Niendorf C.R. \& Spicuzza M.J. 1995. UWG-2, a garnet standard for oxygen isotope ratios: strategies for high precision and accuracy with laser heating. Geochimica et Cosmochimica Acta, 59: 52235231. 
